\title{
CONSUMERS' ATTITUDES TOWARDS BODY AESTHETICS AND COSMETIC PROCEDURES: EVIDENCE FROM BANGLADESH
}

\author{
Md Abu Saleh, School of Management, University of Canberra, Australia \\ Md Irfanuzzaman Khan, School of Management, University of Canberra, Australia \\ Umaira Rahman Chaudhury, London School of Commerce, Dhaka Center, Bangladesh
}

$\underline{\text { dx.doi.org/10.18374/JIBE-17-3.9 }}$

\begin{abstract}
Cosmetic procedures for aesthetical purposes are relatively new in Bangladesh, and only very few studies have been conducted to identify consumers' attitudes to this industry. Bangladesh is a developing country with the potential to become one of the largest economies in the world. It is being heavily influenced by perceptions of beauty as portrayed by the entertainment industry in Europe, United States and India. Their popular motion pictures, drama serials, beauty pageants, fashion houses and cosmetic companies are encouraging consumers to look perfect and the ideal body image for people in Bangladesh is increasingly depicted. The purpose of this research is to understand the key factors influencing consumers' perceptions and attitudes towards cosmetic procedure. The investigation revealed that mass media, social environment and individual factors are the most significant drivers influencing consumers' attitudes. This study adds to the literature on marketing, and provides in-depth insights into how consumers' beliefs are constructed.
\end{abstract}

Keywords: Consumer Attitude, Consumer behaviour, Body aesthetics, Cosmetic procedures, Plastic surgery in Bangladesh 